\title{
Heat Shock Protein Expression and Immunity in Chlamydial Infections
}

\author{
R.W. Peeling ${ }^{1 *}$ and D.C.W. Mabey ${ }^{2}$ \\ ${ }^{1}$ Laboratory Centre for Disease Control, Winnipeg, Manitoba, Canada \\ ${ }^{2}$ London School of Hygiene and Tropical Medicine, London, United Kingdom
}

KEY WORDS

heat shock proteins, Chlamydia trachomatis, immunity

$\mathrm{H}$ eat shock proteins (hsps) are among the most abundant proteins in nature and are highly conserved amongst both eucaryotes and procaryotes. The heat shock response is an important survival mechanism that safeguards the cell or microbe from conditions of stress. The response is triggered transcriptionally and results in the production of newly synthesized proteins within minutes of the cell or microbe encountering a stressful environment. Little is known about the specific functions of these hsps, but it is speculated that they may be involved in vital cell functions, such as the assembly and disassembly of macromolecules and intracellular transport, as well as the proteolysis of aberrant or dysfunctional molecules, thus maintaining the cell in a healthy vegetative state. ${ }^{1}$ They may also have a role in intracellular antigen presentation and processing. ${ }^{2}$ Some hsps are constitutively expressed throughout normal cycles of growth and development, while others are induced under hostile conditions or conditions of stress, such as a change in temperature, $\mathrm{pH}$, oxidative state, conditions of iron or nutrient deprivation, or the presence of enzymes or toxic chemicals.

\section{HEAT SHOCK PROTEINS IN INFECTIOUS DISEASES}

Microbes exist in environments that are constantly changing and have evolved mechanisms such as the heat shock response to bring about rapid adaptation to environmental changes. The invasion of microbes into a human host creates a stressful condition in the host, as well as a hostile environment for the microbes, as the host mounts an immune response against the presence of a foreign body. Thus an upregulation of the heat shock response frequently occurs in both the pathogen and the host in infectious disease. As hsps are highly conserved in nature, it might be expected that a mammalian host would have innate immune tolerance to bacterial hsps, and yet bacterial hsps are among the most highly immunogenic targets for humans. The underlying reason for this is still unclear, and it is speculated that this may have an immune surveillance function in that the immune response to non-self hsp may bring about a rapid protective immune response, perhaps through the scavenging and regulatory function of gamma-delta $T$ cells, the major lymphocyte type found in the host epithelium. ${ }^{2,3}$ To protect the host from destructive immune responses against self-structures, autoreactive $\mathrm{T}$ cells undergo clonal deletion in the thymus early in life, and this self recognition is maintained in the periphery through various regulatory systems. Yet, this system of recognition can sometimes break down, resulting in tissue damage through autoimmune responses. There is some evidence that activation of self-hsp reactive $T$ cells occurs during inflammatory response to infection. CD4 and CD8 T cells with epitope specificity for regions of high homology between microbial and human hsps have been identified in patients with

*Correspondence to: Rosanna W. Peeling, PhD, National Laboratory for Sexually Transmited Diseases, Laboratory Centre for Disease Control, 1015 Arlington St., Winnipeg, Manitoba, Canada. 
diseases such as tuberculosis and leprosy and parasitic diseases such as malaria and onchocerciasis. Thus the delicate balance between a protective immune response against infection and an immune-mediated pathogenic process may represent an interplay between host and pathogen survival mechanisms.

\section{HEAT SHOCK PROTEINS IN CHLAMYDIAL INFECTIONS}

For chlamydia species, experimental work using the mouse pneumonitis strain of Chlamydia trachomatis showed that the heat shock response was inducible within a few minutes of placing cultures at $42-45^{\circ} \mathrm{C}$ and that it was regulated at the level of transcription. ${ }^{4}$ The genes encoding the 10,60 and $70 \mathrm{kD}$ hsps have been cloned and sequenced and found to be the respective homologs of the Escherichia coli groES, groEL, and $d n a K$ genes. ${ }^{5-8}$ These chlamydial genes are constitutively expressed throughout the chlamydial life cycle, and their upregulation during heat stress requires de novo protein synthesis. The groEL and groES genes in chlamydia form an operon with polycistronic messenger RNA transcripts. Data from the chlamydia genome sequencing project showed that there are three copies of the groEL gene, but it is not clear whether they are all expressed during the chlamydia life cycle. Expression of the dnaK gene is increased at least 10 -fold within 10 minutes of exposure to heat shock, and the transcripts have a halflife of approximately 5 minutes. ${ }^{4}$ All three hsps can be found in the outer membrane complexes of elementary and reticulate bodies and are extractable with dithiothreitol or sarkosyl. ${ }^{9}$ These hsps are highly conserved within chlamydia species, exhibiting greater than $95 \%$ identity at the protein level. Of importance to the immunobiology of chlamydiae is that these hsps share approximately $60 \%$ amino-acid identity with their homologs in other bacterial species and approximately $50 \%$ homology with the human hsps.

The DnaK (hsp70) family of proteins are thought to be involved in the binding, folding, and translocation of polypeptides in intracellular transport. ${ }^{2}$ The function of the hsp 70 in chlamydiae is unknown, but it has been shown that it may have a ligand function, as recombinant hsp70 expressed on the surface of E. coli causes the bacteria to bind to human endometrial epithelial cells. ${ }^{10}$ It is there- fore of interest that antibody to this protein was shown to neutralize chlamydia infectivity in vitro. ${ }^{7}$

The GroEL and GroES (hsp10 and hsp60) family of hsps are thought to function as chaperones for newly synthesized oligomeric peptides and have a role in folding and translocation, but the precise role of the chlamydial hsp60 (chsp60) is unknown. Chlamydial hsp60 has been shown to be expressed through the life cycle of chlamydiae, and it is speculated that it may be involved in the reorganization of elementary bodies to reticulate bodies or in the maintenance of the major outer membrane protein in its monomeric structure in the reticulate body. ${ }^{6}$

Serum antibodies to chsp60 have been shown to be associated with the development of adverse sequelae of blinding trachoma, pelvic inflammatory disease (PID), ectopic pregnancy and tubal infertility following ocular and genital $C$. trachomatis infections. ${ }^{9}$ The first evidence for this association came from a study of 13 infertile women, of whom $11(85 \%)$ had an immunoglobulin (Ig) G antibody response to a $57-\mathrm{kD}$ chlamydial protein by immunoblot, compared with one of $11(9 \%)$ healthy pregnant women with a past history of genital chlamydial infection. ${ }^{11}$ It was later shown by cloning and sequence analyses that the $57-\mathrm{kD}$ protein belongs to the GroEL family and that this protein can elicit, in animal models, inflammation and histopathologic damage in infected tissue consistent with the delayed hypersensitivity response seen in human chlamydial disease. ${ }^{12}$

\section{ANIMAL STUDIES}

Since the demonstration that hsp60 can elicit ocular hypersensitivity, animal models of chlamydial disease continue to provide unique opportunities to determine the role of chsp60 in the pathogenesis of chlamydial disease. Recombinant chlamydia hsp70 did not cause inflammation in a primate model of trachoma, but recombinant chsp60 elicited an intense inflammatory response consistent with the immunopathology observed in humans with long-term complications of chlamydial disease. ${ }^{13}$ Delayed type hypersensitivity characterized by mononuclear infiltrates was induced in a monkey model of salpingitis when recombinant chsp60 was injected into subcutaneous pockets containing salpingeal autotransplants of sensitized monkeys but not in naive monkeys. ${ }^{14}$ In studies with a primate model of chronic PID, it was shown that there 
was a heterogeneity in chsp60 antibody responsiveness among primates experimentally infected with C. trachomatis. $^{15}$ There were three patterns of chsp60 antibody response: nonresponders, transient responders, and persistent responders. Similarly, heterogeneity in disease outcome following genital chlamydial infection has been observed in humans, since only a subset of infected women develop long-term sequelae of salpingitis, ectopic pregnancy, or tubal infertility. In this primate model, only a prolonged or persistent chsp60 antibody response correlated with persistent chlamydial infection in the fallopian tubes. Monkeys with C. trachomatis in their fallopian tubes were more likely to have an intense chsp60 antibody response that persisted longer. Among the chsp60 responders, a more intense chsp60 response correlated with a more severe gross pathology before treatment. Compared with the serologic response using the microimmunofluorescence (MIF) assay, the chsp60 antibody response appeared to be a more specific marker for chlamydial tubal infection. The similarity of disease outcome observed in this animal model with that in human studies makes this a useful model for further work on the role of chsp60 in the pathogenesis of chlamydial disease and may yield clues to the prevention of chlamydiaassociated tubal infertility.

\section{ASSOCIATION OF SEROLOGIC RESPONSES TO CHLAMYDIAL HEAT SHOCK PROTEIN 60 WITH ADVERSE OUTCOMES IN THE EYE AND GENITAL TRACT}

Toye et al. developed an enzyme immunoassay using purified recombinant chsp60 as antigen and confirmed that serum antibody to chsp60 was strongly associated with the development of tubal infertility in women seropositive for $C$. trachomatis. ${ }^{16}$ Several other studies since then have demonstrated the relationship between the prevalence of serum IgG antibody response to chsp60 and the progressive development of adverse reproductive sequelae in women (Fig. 1). ${ }^{11,16,17-22}$ Dieterle et al. showed that there was no significant difference in serum IgG antibodies to both chsp60 and chsp70 in women with chlamydia-associated chronic salpingitis and/or tubal occlusion when compared with those with no evidence of tubal occlusion. ${ }^{23}$ However, the presence of serum IgA antibody responses to chsp60 was correlated with chlamydia-

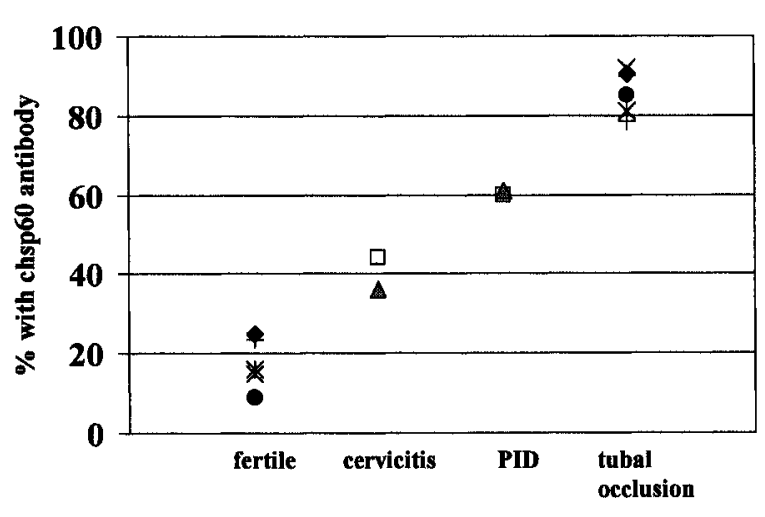

Fig. 1. The prevalence of chsp60 antibody in women with a past history of genital chlamydial infection who are fertile, who have acute cervicitis or PID, or who have been diagnosed with ectopic pregnancy or tubal infertility as a result of tubal occlusion. Data drawn from references $11(\bullet), 16$ (*), $17(\Delta), 18(\square), 19(X), 20(\$), 21(+)$.

associated chronic salpingitis and/or tubal occlusion.

Two studies examined this association prospectively. In a study of 280 women with a history of genital chlamydia infection, the presence of serum IgG antibodies to chsp60 was predictive of the development of $\mathrm{PID}$, with an odds ratio of $2.12 .{ }^{24} \mathrm{In}$ men, serum antibody to chsp60 was not associated with acute urethritis but was associated with the development of chronic urethritis on follow-up at 10-92 days after diagnosis and treatment of urethritis. ${ }^{25}$ Of 43 men who showed signs of inflammation in their urethral smear on follow up and were seropositive for $C$. trachomatis, 23 had detectable serum chsp60 antibodies. Twenty of these 23 patients $(87 \%)$ developed chronic urethritis, compared with $11 / 20$ (55\%) who had no chsp60 antibodies $(P<.05)$.

In ocular chlamydial infection, the presence of serum IgG antibodies was associated with the development of conjunctival scarring in a case-control study of 296 children and adults from a trachoma endemic area of Gambia. ${ }^{26}$ Of interest, the prevalence of chsp60 antibody in the cases of trachomatous scarring was only $32 \%$, compared with approximately $80 \%$ in women with chlamydiaassociated tubal occlusion, as shown in Figure 1. The reason for this is not clear. It may reflect the smaller area of epithelium infected. Alternatively, it is possible that other factors, such as recurrent cycles of bacterial infection, may contribute to the progression of conjunctival scarring in trachoma. 
TABLE I. Summary of antibody response to chsp60 fragments or by peptide mapping in women with various consequences of genital chlamydial infection

\begin{tabular}{|c|c|c|c|c|}
\hline \multirow[b]{2}{*}{ Study } & \multicolumn{4}{|c|}{ Peptide reactivity (no. reacted/no. tested) } \\
\hline & Peptides $^{\mathbf{a}}$ & PID & Infertility & Fertile Controls \\
\hline \multirow[t]{5}{*}{ Cerrone et al. ${ }^{6}$} & $|-5|$ & $0 / 8$ & Not done & Not done \\
\hline & $50-143$ & $0 / 8$ & & \\
\hline & $50-266$ & $0 / 8$ & & \\
\hline & $274-402$ & $4 / 8 \quad(50 \%)$ & & \\
\hline & $405-544$ & $5 / 8 \quad(63 \%)$ & & \\
\hline \multirow[t]{5}{*}{ Arno et al. ${ }^{22}$} & $2-544$ & Not done & $|/ 2|(5 \%)$ & $0 / 9$ \\
\hline & $101-544$ & & $|/ 2|(5 \%)$ & $0 / 9$ \\
\hline & $201-544$ & & ||$/ 2 \mid(52 \%)$ & $0 / 9$ \\
\hline & $301-544$ & & $0 / 21$ & $0 / 9$ \\
\hline & $401-544$ & & ||$/ 2 \mid(52 \%)$ & $1 / 9(11 \%)$ \\
\hline \multirow[t]{2}{*}{ Domeika et al. ${ }^{32}$} & $|5|-162$ & $4 I / / 29(32 \%)$ & Not done & \\
\hline & $260-271$ & $51 / 129(40 \%)$ & & \\
\hline \multirow[t]{3}{*}{ Witkin et al. ${ }^{33}$} & $260-271$ & $2 / 17(12 \%)$ & $2 / 8(25 \%)$ & $0 / 3$ \\
\hline & & & $8 / 13(62 \%)$ & \\
\hline & & & $2 / 7 \quad(29 \%)$ & \\
\hline
\end{tabular}

aNumbers denote positions in the amino acid sequence.

'Cases for Cerrone et al. are women with PID; for Artio et al., women with tubal infertility; for Domeika et al., women with PID; and for Witkin et al., women with spontaneous abortion.

Does antibody response to chsp60 have any effect on the success of in vitro fertilization? The answer is equivocal. Witkin showed that the presence of IgA antibody at the cervix was associated with a poor outcome of in vitro fertilization. . $^{27,28}$ Cervical chsp60 IgA was detected in $36(28 \%)$ of 130 women with unsuccessful embryo transfers, three (30\%) of 10 women with spontaneous abortions, seven (33\%) of 21 women with biochemical pregnancies, five (33\%) of 15 women whose oocytes failed to become fertilized, and 26 (26\%) of 99 women who did not become pregnant, compared with five $(7 \%)$ of 68 women who had successful term births. Claman showed that in vitro fertilization was more successful in women with serum $\operatorname{IgG}$ antibody response to chsp $60 .{ }^{29}$ It has been speculated that cell-mediated immunity is depressed in pregnancy to lower the risk of rejection of the fetus, and thus pregnant women may have a predominantly $\mathrm{TH} 2$ response to infection. Although it remains unclear how the presence of cervical or serum chsp60 antibody may have an effect on fertilization outcome, Witkin et al. speculated that asymptomatic chlamydial infection or reactivation of the hsp60 response may induce an inflammatory reaction in the uterus which in turn impairs and/or rejects embryo transplant. ${ }^{28}$

Is the intensity of the chsp60 response correlated with the severity of the outcome? In a prospective study of 157 women with a clinical diag- nosis of PID, 73 women had laparoscopically confirmed salpingitis and were assessed for perihepatitis. ${ }^{30} \mathrm{~A}$ chsp60 antibody absorbance reading of 0.5 or greater was detected in 12 of 18 (67\%) women with laparoscopically confirmed perihepatitis, compared with 12 of $43(28 \%)$ in the salpingitis only group $(P=.005)$. The mean chsp60 antibody absorbance was also significantly higher in the perihepatitis group $(P=.02)$. Perihepatitis correlated with moderate to severe pelvic adhesions but not with peritoneal pus, suggesting a more intense inflammatory response in these patients than in women with salpingitis alone. In a study of human PID, the highest chsp60 titers were found in $80 \%$ of women who had occluded tubes. ${ }^{17}$ The strong association of chsp60 antibody and tubal occlusion was independent of MIF IgG antibody as shown in other studies. ${ }^{16}$

Several studies attempted to identify the immunodominant regions of the protein and correlate these regions with potential homology and hence cross-reactivity to the human hsp60. The results are not conclusive (Table 1). Cerrone et al. cloned the entire chsp60 from $C$. trachomatis serovar $\mathrm{L} 2$ as well as fragments of the protein and found that among eight women with chlamydial PID, four reacted to the fragment that consisted of amino acids 274-402, and five reacted to the fragments with amino acids 405-544. ${ }^{6}$ The amino terminal of the chsp60 did not appear to be immunogenic in their 
study. Although this was confirmed by Arno's study also using cloned fragments, studies using synthetic peptides showed that there are many immunoreactive regions, including the amino terminal, each of which have the potential to cause crossreactivity with the human hsp. ${ }^{22,31,32}$ Amino acids 260-271 were identified as an immunodominant peptide conserved between human and chlamydial hsp $60 .^{33}$

\section{ASSOCIATION OF CELL-MEDIATED IMMUNITY TO CHLAMYDIAL HEAT SHOCK PROTEIN 60 WITH DISEASE OUTCOME}

Holland et al. found that subjects with trachomatous scarring had weaker cell-mediated immune responses, in terms of lymphocyte proliferation and interferon-gamma production, to chsp60 and other chlamydial antigens than age- and sex-matched controls from endemic communities. ${ }^{34}$ Moreover, subjects who spontaneously cleared ocular chlamydial infection had stronger lymphoproliferative responses to chsp60, the major outer membrane protein, and whole organisms than those with persistent infection. ${ }^{35}$ Studies in knockout mice showed that cell-mediated immunity is important in clearance of infection. ${ }^{36}$ Thus, subjects with trachomatous scarring may have a predominantly TH2 response to chlamydial antigens, impairing their ability to clear the infection. Previous studies have shown that women with tubal infertility had higher levels of chlamydial antibody than fertile controls, consistent with the hypothesis that these women had a predominantly TH2 response to chlamydial infection. ${ }^{11,16,37}$ Witkin et al. showed that women with laparoscopically verified salpingitis were more likely to have a lymphoproliferative response to chsp60 than women who had cervicitis or recurrent abortions. ${ }^{38}$ These responses were shown to be stimulated by various epitopes, some of which are conserved between human and chlamydial hsp60. ${ }^{39}$

\section{GENETIC RESTRICTION OF IMMUNE RESPONSES TO CHLAMYDIAL HEAT SHOCK PROTEIN 60 IN CHLAMYDIAL INFECTION}

The heterogeneity in chlamydial disease outcome suggests that there may be a genetic susceptibility to long-term complications of chlamydial disease. It is speculated that this genetic restriction may be linked to the control of immune response genes. Genetic restriction in immune responses to chsp60 may partially explain the heterogeneity in disease outcome following genital chlamydial infection. In a mouse model, it was shown that antibody response to the chlamydial hsp60 and hsp70 are tightly controlled by genes in the H-2 locus and that the trait for high antibody response to hsps was dominant. ${ }^{40}$ It is estimated that only a third of women with cervical infection develop PID, of whom one third will progress to tubal occlusion. ${ }^{37}$ The development of PID has been shown to correlate with the human leukocyte antigen A-31 allele, but this is not correlated with the chsp60 antibody response. ${ }^{18}$

In studies of trachomatous scarring in trachoma endemic communities in Gambia, chsp60 antibody response was positively correlated with human leukocyte antigen class-II allele DR $\beta 1^{*} 0701$ and negatively correlated with DQ $1 * 0301$ and DQß1*0501. ${ }^{26,41}$ However, as none of these alleles were directly correlated with evidence of disease, susceptibility to disease due to the genetic regulation of host immune response may be complex.

Although other host or microbial determinants likely contribute to the development of immunopathology following genital chlamydial infection, the data reviewed thus far suggest that through genetic control of their immune response, some individuals with chlamydial infection appear to be unable to clear their infection, resulting in a persistently infected state in which the host and pathogen achieve a delicate balance as previously described. In turn, this may lead to the increased expression of both host and chlamydial chsp60. From this point, several possibilities for immunemediated damage exist, which are not by any means mutually exclusive.

\section{POSSIBLE MECHANISMS OF PATHOGENESIS}

The origin of continued antigenic stimulation to sustain the antibody response to chsp 60 in the absence of clinically inapparent infection remain undefined. Beatty et al. showed that in cell cultures persistently infected with $C$. trachomatis the expression of hsp60 is maintained at normal levels, while other proteins, such as the major outer membrane protein, are downregulated. ${ }^{42}$ This has led to the suggestion that the chsp 60 antibody response is either a marker of persistent chlamydial infection 
or is somehow causally related to the development of immunopathology in chlamydial disease, perhaps through an autoimmune response. It is also possible that chsp60 or other chlamydial antigens may be involved in immune complexes that cause inflammation in the infected tissues. ${ }^{43}$ These mechanisms may not be mutually exclusive.

\section{Autoimmunity}

Since hsps are highly conserved, antibody response to chsp60 may be a marker of autoimmune responses initiated by cross-reactivity between chsp60 and host cell hsp60 epitopes. The induction of autoimmune responses as a result of molecular mimicry between bacterial hsp and human hsp has been documented. ${ }^{2}$ Lin et al. showed that the induction of autoreactive B cells by simultaneous injection of a self and a heterologous protein allows the priming of autoreactive $\mathrm{T}$ cells. ${ }^{44}$ In a mouse model, tolerance to mouse hsp60 was broken by the simultaneous injection of mouse and chlamydial hsp60. ${ }^{45}$ Although immunogenic epitopes that are cross-reactive between chlamydial and human hsp60 have been identified in a number of studies as previously described, the activation of autoreactive ' $\mathrm{T}$ cells is a complex process, and high homology between bacterial and human proteins may not necessarily lead to cross-reactivity. Other host determinants, such as the ability of peptides to bind to major histocompatibility complex molecules, are also important in the process. Given the frequency with which humans encounter microbial pathogens, the highly conserved nature of hsp, and the fact that antibodies and $T$ cells with specificity for cross-reactive epitopes between microbial and human hsp have been found in healthy individuals, it is unlikely that hsps are the primary inducers of autoimmune responses in infection. ${ }^{2}$ However, it is possible that hsps may have a role in priming selfhsp reactive $T$ cells or in exacerbating an ongoing autoimmune process.

\section{The Role of Chlamydial Heat Shock Protein 60 as a Marker for Persistent Infection}

Evidence for persistent chlamydial infection has been described. ${ }^{46} C$. trachomatis DNA and antigen have been found in the fallopian tubes of women with postinfectious tubal infertility, presumably as a result of a persistent chlamydial infection in the fallopian tubes. ${ }^{47}$ In a study of human PID, MIF
IgA response in serum is significantly correlated with the finding of chsp60 IgG response in women with confirmed PID but not among women with acute chlamydial infection. Since serum IgA has a short half-life, the data suggest that these women may be harboring a persistent chlamydial infection. Repeated cervical chlamydial infection has been identified as a risk factor for human PID, as well as for tubal obstruction in a monkey model of salpingitis. $^{18,48}$ Thus, chsp60 antibody response may be useful to identify individuals at risk of long-term complications of chlamydial disease. ${ }^{49}$

Other alternative but not mutually exclusive hypotheses for the role of chsp60 in immunopathology include, first, that the chsp60 antibody response is part of a highly polarized $\mathrm{T}$ cell response that causes tissue fibrosis as seen in schistosomiasis. ${ }^{50} \mathrm{~T}$-cell responses to chsp60 may mediate the inflammatory pathology associated with ocular and genital chlamydial infection. Studies from trachoma endemic areas showed that individuals with scarring trachoma have depressed $\mathrm{T}$-cell responses to chlamydial antigens, including chsp60, compared with individuals who were able to resolve their chlamydial infections, suggesting that a predominantly $\mathrm{TH} 2$ response fails to clear chlamydial infection. ${ }^{34,35}$

It may be possible to distinguish the underlying mechanism of autoimmunity or persistent infection through studies of antimicrobial treatment. If persistent chlamydial infection, characterized by antibody response to chsp60, was the cause of immunopathology in acute chlamydial PID, then antimicrobial treatment that eradicates the infection should be effective in modulating the antibody response and the subsequent development of tubal pathology. On the other hand, if chsp60 itself is the cause of inflammation in the absence of an active infection, possibly because of an autoimmune response to the human hsp60, then the effect of treatment on chsp60 antibody response and immunopathology would be limited.

\section{CONCLUSION}

Heat shock proteins are expressed constitutively throughout the life cycle of chlamydiae, as well as under conditions of stress. Antibody to chsp70 is associated with protective immunity in vitro, while antibody to the chsp60 is associated with the development of immunopathology in chlamydial in- 
fection, leading to blinding trachoma, PID, ectopic pregnancy, and tubal infertility. There is evidence to suggest that the chsp60 antibody response may be useful as a marker of persistent infection in the fallopian tubes and therefore may be useful to identify women at risk of developing tubal pathology. In such women, it may be possible to initiate intervention, such as more aggressive antimicrobial treatment, before tubal occlusion occurs. The efficacy of antimicrobial regimens presently recommended for the treatment of human PID is largely based on the resolution of symptoms. Whether the organism is actually eradicated from the fallopian tubes, hence preserving fertility, is uncertain. Further studies are required to determine whether this response may be useful to monitor treatment efficacy in human PID. The role of chsp60 in the development of immunopathology remains unclear. Studies are needed to determine whether chsp60 is the inducing or exacerbating antigen at the site of inflammation, how chsp molecules are presented to and processed by the host immune system, and how that may result in the different outcome of protective and damaging immune responses observed in chlamydial infection. This knowledge will be important to further our understanding of chlamydial disease and may offer opportunities for disease control and prevention.

\section{REFERENCES}

1. Lindquist $S$. The heat shock response. Ann Rev Biochem 1986;55:1151-1191.

2. Zïgel U, Kaufmann SHE. Role of heat shock proteins in protection from and pathogenesis of infectious diseases. Clin Microbiol Rev 1999;12:19-39.

3. Young RA, Elliott TJ. Stress proteins, infection and immune surveillance. Cell 1989;59:5-8.

4. Engel JN, Pollack J, Perara E, Ganem D. Heat shock response of murine Chlamydia trachomatis. J Bacteriol 1990;172:6959-6972.

5. Morrison RP, Su H, Lyng K, Yuan Y. The Chlamydia trachomatis hyp operon is homologous to the groE stress response operon of Escherichia coli. Infect Immun 1990; 58:2701-2705.

6. Cerrone MC, Ma JJ, Stephens RS. Cloning and sequence of the gene for heat shock protein 60 from Chlamydia trachomatis and immunological reactivity of the protein. Infect Immun 1991;59:79-90.

7. Danilition SL, Maclean IW, Peeling R, Winston S, Brunham RC. The 75-kilodalton protein of Chlamydia trachomatis: a member of the heat shock protein 70 family? Infect Immun 1990;58:189-196.

8. LaVerda D, Byrne GI. Use of monoclonal antibodies to facilitate identification, cloning and purification of Chlamydia trachomatis hsp10. J Clin Microbiol 1997;35:12091215.

9. Brunham RC, Peeling RW. Chlamydia trachomatis antigens: role in immunity and pathogenesis. Infect Agents Dis 1994;3:218-233.

10. Schmiel DH, Knight ST, Raulston JE, Choong J, David CH, Wyrick PB. Recombinant Escherichia coli clones expressing Chlamydia trachomatis gene products attach to human endometrial epithelial cells. Infect Immun 1991; 59:4001-4012.

11. Brunham RC, Maclean IW, Binns B, Peeling RW. Chlamydia trachomatis: its role in infertility. J Infect Dis 1985; 152:1275-1282.

12. Morrison RP, Belland RJ, Lyng K, Caldwell HD. Chlamydial disease pathogenesis. The 57-kd chlamydial hypersensitivity antigen is a stress response protein. J Exp Med 1989;170:1271-1283.

13. Taylor H, Maclean IW, Brunham RC, Pal S, WhittumHudson J. Chlamydial heat shock proteins and trachoma. Infect Immun 1990;58:3061-3063.

14. Patton DL, Sweeney YT, Kuo CG. Demonstration of delayed hypersensitivity in Chlamydia trachomatis salpingitis in monkeys. a pathogenic mechanism of tubal damage. J Infect Dis 1994;169:680-683.

15. Peeling RW, Patton DL, Cosgrove Sweeney Y'T, Brunham RC, Stamm WE. Antibody response to the chlamydial heat shock protein 60 in an experimental PID model in monkeys ( $M$. nemistrina). Proceedings of the 11 th meeting of the International Society for STD Research, New Orleans, 1995, abstract \#008.

16. Toye B, Laferriere C, Claman P, Jessamine P, Peeling R. Association between antibody to the chlamydial heat-shock protein and tubal infertility. J Infect Dis 1993;168:1236-1240.

17. Eckert L, Hawes SE, Wolner-Hanssen P, et al. Prevalence and correlates of antibody to chlamydial heat shock protein in women attending sexually transmitted disease clinics and women with confirmed pelvic inflammatory disease. J Infect Dis 1997;175:1453-1458.

18. Kimani J, Maclean IW, Bwayo JJ, et al. Risk factors for G. trachomatis pelvic inflammatory disease among sex workers in Nairobi, Kenya. J Infect Dis 1996;173:14371444.

19. Friedank HM, Clad A, Herr AS, Weidman-Al-Ahmad M, Jung B. Immune response to Chlamydia trachomatis heat shock protein in infertile female patients and influence of Chlamydia pneumoniae antibodies. Eur J Infect Dis Clin Microbiol 1995;14:1063-1069.

20. Brunham RC, Peeling R, Maclean I, Kosseim ML, Paraskevas M. Chlamydia trachomatis-associated ectopic pregnancy: serologic and histologic correlates. J Infect Dis 1992;165:1076-1081.

21. Ault KA, Statland BD, King MM, Dozier DI, Joachims ML, Gunter J. Antibodies to the chlamydial 60 kilodalton heat shock protein in women with tubal factor infertility. Infect Dis Obstet Gynecol 1998;6:163-167.

22. Arno J, Yuan Y, Cleary RE, Morrison RP. Serologic re- 
sponses of infertile women to the 60 -kd chlamydial heat shock protein (hsp60). Fertil Steril 1995;64:730-735.

23. Dieterle $S$, Wollenhaupt J. Humoral immune response to the chlamydial heat shock proteins hsp60 and hsp70 in chlamydia-associated chronic salpingitis with tubal occlusion. Hum Reprod 1996;11:1352-1356.

24. Peeling RW, Kimani J, Plummer F, et al. Antibody to chlamydial hsp60 predicts an increased risk for chlamydial pelvic inflammatory disease. J Infect Dis 1997; 175:1153-1158.

25. Horner PJ, Cain D, McClure M, et al. Association of antibodies to Chlamydia trachomatis heat shock protein $60 \mathrm{kD}$ with chronic nongonococcal urethritis. Clin Infect Dis 1997;24:653-660.

26. Peeling RW, Bailey R, Conway JD, et al. Antibody response to the $60-\mathrm{kDa}$ chlamydial heat-shock protein is associated with scarring trachoma. J Infect Dis 1998;177: 256-259.

27. Witkin SS, Kligman I, Grifo JA, Rosenwaks Z. Chlamydia trachomatis detected by polymerase chain reaction in cervices of culture-negative women correlates with adverse in vitro fertilization outcome. J Infect Dis 1995; 171:1657-1659.

28. Witkin SS, Sultan KM, Neal GS, Jeremias J, Grifo JA, Rosenwaks Z. Unsuspected Chlamydia trachomatis infection and in vitro fertilization outcome. Fertil Steril 1994; 171:1208-1214.

29. Claman P, Amimi MN, Peeling RW, Toye B, Jessamine P. Does serologic evidence of remote chlamydia trachomatis infection and its heat shock protein (CHSP60) affect in vitro fertilization-embryo transfer outcome? Fertil Steril 1996;65:146-149.

30. Money DM, Hawes SE, Eschenbach DA, et al. Antibodies to the chlamydial $60 \mathrm{kd}$ heat shock protein are associated with laparoscopy confirmed perihepatitis. Am J Obstet Gynecol 1997;76: 870-877.

31. Yi Y, Zhong G, Brunham RC. Continuous B-cell epitopes in Chlamydia trachomatis heat shock protein 60 . Infect Immun 1993;61:1117-1120.

32. Domeika M, Domeika K, Paavonen J, Mardh P-A, Witkin SS. Humoral immune response to conserved epitopes of Chlamydia trachomatis and human $60-\mathrm{kDa}$ heatshock protein in women with pelvic inflammatory disease. J Infect Dis 1998;177:714-719.

33. Witkin SS, Askienazy-Elbhar M, Henry-Suchet J, Belaisch-Allart J, Tort-Grumbach J, Sarjdine K. Circulating antibodies to a conserved epitope of the Chlamydia trachomatis $60 \mathrm{kDa}$ heat shock protein (hsp60) in infertile couples and its relationship to $C$. trachomatis surface antigens and the Escherichia coli and human HSP60. Hum Reprod 1998;13:1175-1179.

34. Holland MJ, Bailey RL, Hayes LJ, Whittle HC, Mabey DCW. Conjunctival scarring in trachoma is associated with depressed cell-mediated immune responses to chlamydial antigens. J Infect Dis 1993;168:1528-1531.

35. Bailey RL, Holland MJ, Whittle HC, Mabey DCW. Subjects recovering from human ocular chlamydial infection have enhanced lymphoproliferative responses to chlamydial antigens compared with those of persistently diseased controls. Infect Immun 1995;63:389-392.

36. Morrison RP, Feilzer K, Tumas DB. Gene knockout mice establish a primary protective role for major histocompatibility class II restricted responses in Chlamydia trachomatis genital tract infection. Infect Immun 1995; 63:4661-4668.

37. Cates W, Wasserheit JN. Genital chlamydial infections: epidemiology and reproductive sequelae. Am J Obstet Gynecol 1991;164:1771-1781.

38. Witkin SS, Jeremias J, Toth M, Ledger WJ. Cellmediated immune response to the recombinant $57 \mathrm{kDa}$ heat-shock protein of Chlamydia trachomatis in women with salpingitis. J Infect Dis 1993;167:1379-1383.

39. Witkin SS, Jeremias J, Toth M, Ledger WJ. Proliferative response to conserved epitopes of the Chlamydia trachomatis and human 60-kilodalton heat-shock proteins by lymphocytes from women with salpingitis. Am J Obstet Gynecol 1994;171:455-460.

40. Zhong G, Brunham RC. Antibody responses to the chlamydial heat shock proteins hsp60 and hsp70 are H-2 linked. Infect Immun 1992;60:3143-3149.

41. Conway DJ, Holland MJ, Campbell AE, et al. HLA class I and II polymorphisms and trachomatous scarring in a $C$. trachomatis-endemic population. J Infect Dis 1996;174:643-646.

42. Beatty WL, Morrison RP, Byrne GI. Immunoelectronmicroscopic quantitation of differential levels of chlamydial proteins in a cell culture model of persistent Chlamydia trachomatis infection. Infect Immun 1994;62: 4059-4062.

43. Magro GM, Crowson AN, Peeling R. Vasculitis as the basis of cutaneous lesions in Reiter's disease. Hum Pathol 1995;26:633-638.

44. Lin RH, Mamula MJ, Hardin JA, Janeway CA. Induction of autoreactive B cells allows priming of autoreactive T cells. J Exp Med 1991;173:1433.

45. Yi Y, Yang X, Brunham RC. Autoimmunity to heat shock protein 60 and antigen-specific production of interleukin-10. Infect Immun 1997;65:1669-1674.

46. Beatty WL, Morrison RP, Byrne GI. Persistent chlamydiae: from cell culture to a paradigm for chlamydial pathogenesis. Microbiol Rev 1994;58:686-699.

47. Patton DL, Askienazy-Elbhar M, Henry-Suchet JH, et al. Detection of $G$. trachomatis in fallopian tube tissue in women with post infectious infertility. Am J Obstet Gynecol 1994;171:95-101.

48. Patton DL, Kuo CG, Wang SP, Halbert HA. Distal tubal obstruction induced by repeated Chlamydia trachomatis salpingeal infections in pig-tailed macaques. J Infect Dis $1987 ; 155: 1292$.

49. Claman P, Honey L, Peeling RW, Jessamine P, Toye B. The presence of serum antibody to the chlamydial heat shock protein (CHSP60) as a diagnostic test for tubal factor infertility. Fertil Steril 1997;67:501-504.

50. Wynn TA, Cheever AW, Jankovic D, et al. An IL-12based vaccination method for preventing fibrosis induced by schistosome infection. Nature 1995;376:594 596. 


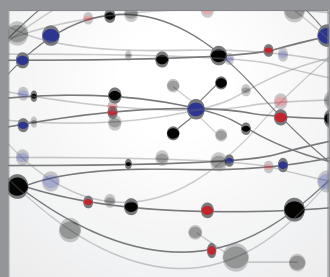

The Scientific World Journal
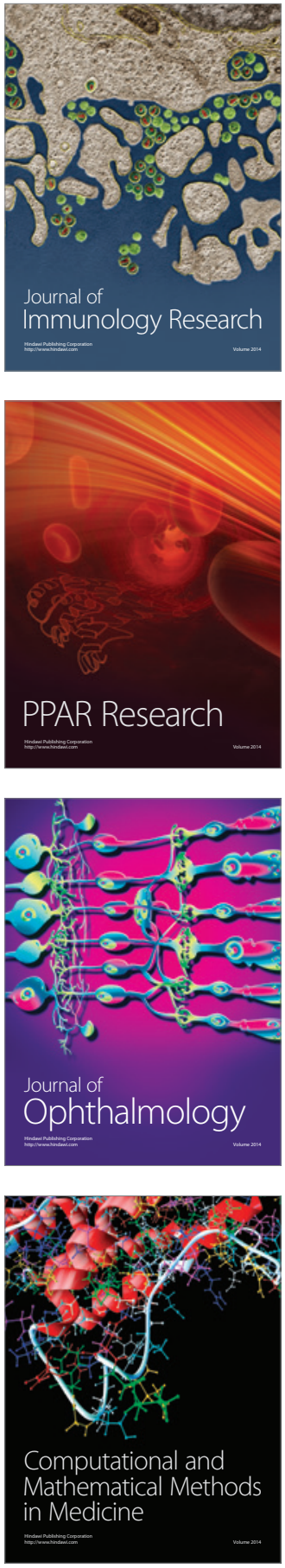

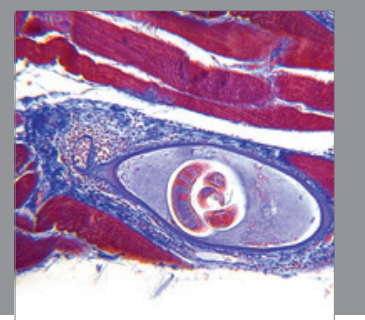

Gastroenterology

Research and Practice
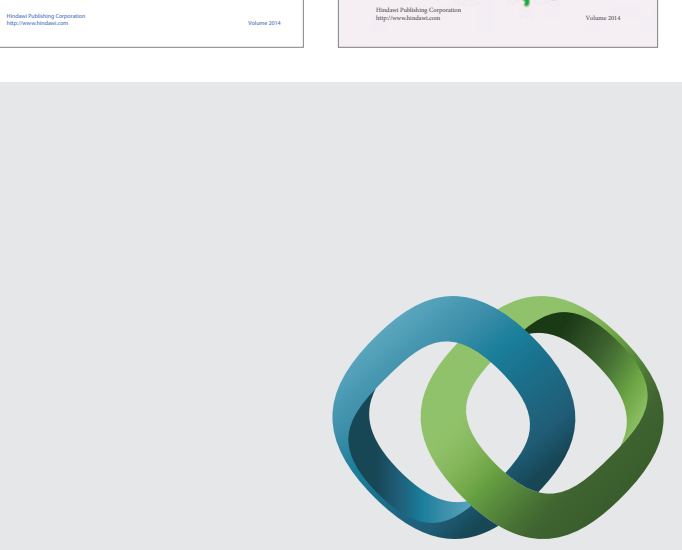

\section{Hindawi}

Submit your manuscripts at

http://www.hindawi.com
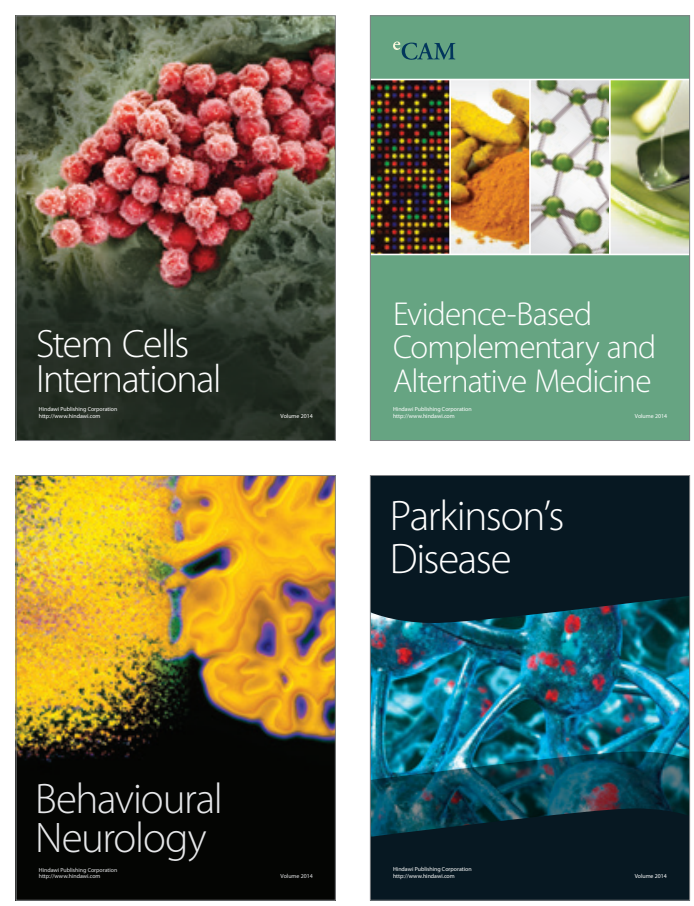

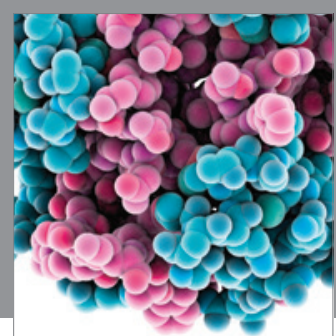

Journal of
Diabetes Research

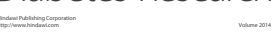

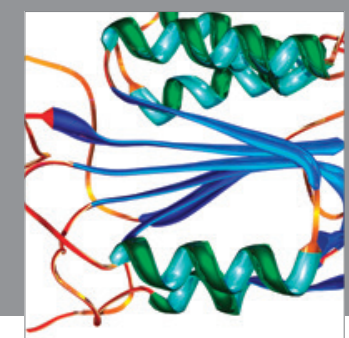

Disease Markers
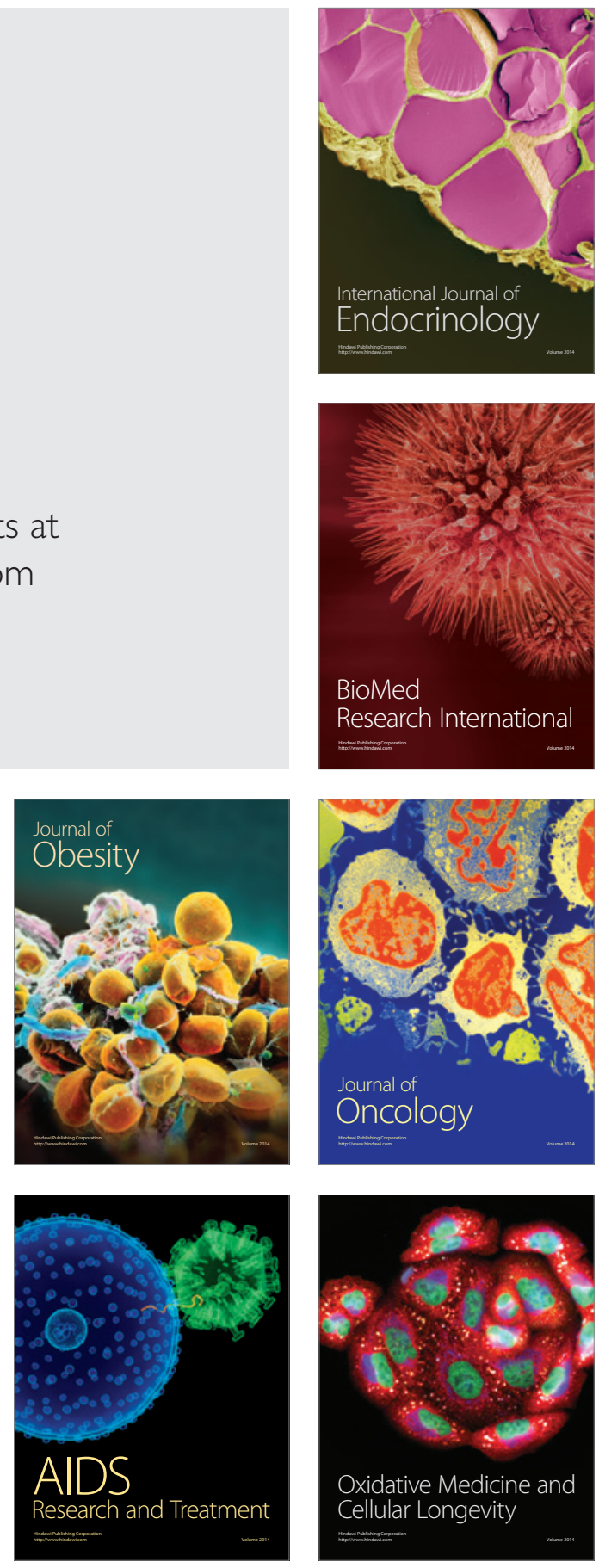